\title{
REGIONALISMO PAULISTA E POLÍTICA PARTIDIÁRIA NOS ANOS VINTE*
}

James P. Woodard

Brown University

\section{Resumo}

Os conflitos políticos do final dos anos vinte entre o Partido Republicano Paulista e o Partido Democrático de São Paulo tiveram um papel muito maior no cenário político dos anos 30 do que a historiografia atual tem apontado. Em particular, estes conflitos possibilitaram a mobilização do estado de São Paulo contra o governo federal chefiado por Getúlio Vargas, pois encorajaram a especie de identidade regionalista/nacionalista que serviria de grito de protesto para os rebeldes paulistas de 1932.

\section{Pallavras-Chave}

\section{São Paulo • Regionalismo • Política}

\section{Abstract}

The political conflicts of the late 1920s between the Paulista Republican Party and the Democratic Party of São Paulo played a much larger role in the politics of the 1930s than indicated by the existing historiography. In particular, these conflicts helped to lay the groundwork for the mobilization of the state of São Paulo against the federal government headed by Getúlio Vargas by encouraging the kind of regionalist-cum-nationalist identification that would serve as a rallying cry for the Paulista rebels of 1932.

Keywords

São Paulo (Brazil - State) • Regionalism • Politics

\footnotetext{
*Este trabalho - uma adaptação de um paper que apresentei ao congresso da Associação de Estudos Brasileiros em abril de 2002 - deve muito às pesquisas que fiz para minha tese de doutoramento, defendida em setembro de 2003. Gostaria de expressar meus agradecimentos à banca examinadora: Thomas E. Skidmore, Barbara Weinstein, e R. Douglas Cope. Devo também agradecer a contribuição valiosa do meu amigo João Felipe Gonçalves, que leu e corrigiu uma tradução preliminar deste artigo.
} 
No final dos anos 20 o estado de São Paulo vivenciou um importante conflito político entre o estabelecido Partido Republicano Paulista e o recém-fundado Partido Democrático de São Paulo. Embora este conflito político não tendo sido totalmente sem precendentes, e embora a organização do partido político dissidente não tenha sido tão inusitada ou importante como se tem acreditado, o conseqüente conflito político foi de considerável importância. Pela primeira vez desde o final do Império, viu-se um grupo político organizado por todo o estado ser capaz de apresentar-se como uma oposição ideológica, ao contrário da política clientelística do PRP.

As interpretações do PD têm sido múltiplas, indo desde evocações da "classe média ascendente" até as mais variadas especulações sobre mudanças sociais, econômicas e políticas. Cada uma delas contribuiu a seu modo para a historiografia do período, mas tem-se praticamente negligenciado o papel que o partido desempenhou para efetuar mudanças críticas na prática política do estado. Em particular, a formação da Frente Única entre o PD e o PRP em 1932 e a persistência de 1930 como ponto crítico na periodização da história contemporânea do Brasil tem levado alguns historiadores a acreditar que os conflitos dos anos 20 exerceram pouca ou 42 nenhuma influência na história da década seguinte.

Como resultado, pouca atenção tem sido dada aos efeitos deste conflito a longo prazo, isto é, à maneira como as lutas políticas dos anos 20 prefiguraram e até prepararam o caminho para as lutas políticas subseqüentes. Pesquisas nessa direção revelam que os conflitos políticos dos anos 20 tiveram um papel muito maior no cenário político dos anos 30 do que a historiografia atual tem apontado. Talvez ainda mais importante seja o fato de que estes conflitos possibilitaram a mobilização do estado de São Paulo na revolta contra o governo federal chefiado por Getúlio Vargas, pois criaram as estruturas organizacionais que foram essenciais para a formação da rebelião (o Centro das Indústrias do Estado de São Paulo e o próprio $\mathrm{PD}^{1}$ ) e encorajaram o tipo de identidade regio-

\footnotetext{
${ }^{1}$ MORGAN, Arthur. Os engenheiros de S. Paulo em 1932: pela lei e pela ordem. São Paulo: 1934, pp. 49-50; OLIVEIRA, Clovis de. A indústria e o movimento constitucionalista de 1932. São Paulo: Serviço de Publicações do CIESP/FIESP, 1956; WEINSTEIN, Barbara. For social peace in Brazil: industrialists and the remaking of the working class in São Paulo, 1920-1964. Chapel Hill: University of North Carolina Press, 1996, pp. 63-64; PRADO, Maria Lígia Coelho. A democracia ilustrada: o Partido Democrático de São Paulo, 1926-1934. São Paulo: Editora Ática, 1986, capítulo 2, parte B; SANTOS, Francisco Martins dos. História de Santos, 15321936. São Paulo: Empreza Graphica da Revista dos Tribunaes, 1937, capítulo 26.
} 
nalista/nacionalista que serviria de grito de protesto para os rebeldes paulistas de 1932. Em discursos, cartas, artigos de jornais e material iconográfico, as principais figuras políticas do final dos anos 20, tanto da situação quanto da oposição, utilizaram-se do discurso da grandeza paulista e de imagens como a do bandeirante para reforçar suas tentativas de obter poder. Esse tipo de identidade regionalista antecipou o chauvinismo paulista de 1931 a 1932, usado por líderes estaduais na mobilização da população de São Paulo na rebelião contra o governo federal.

Os participantes do conflito político no final dos anos 20 certamente não inventaram este tipo de identidade (estava presente no movimento separatista do fim do Império, como demonstra Cássia Chrispiniano Adduci no seu livro A “pátria paulista”, e é onipresente nos anos seguintes, segundo o que já começa a sinalizar a atual pesquisa de Barbara Weinstein ${ }^{2}$ ), mas garantiram que ele estivesse na agenda política do final dos anos 20. Mais notavelmente, eles o fizeram não apenas em pequenas discussões internas da elite e em edições particulares distribuídas aos amigos e outros escritores, mas também no âmbito que alguns chamariam de uma "esfera pública": na crescente imprensa periódica do período, em comícios públicos freqüentados por membros das chamadas "classes conservadoras" e das "classes populares", e em material de propaganda direcionado a um público mais abrangente. ${ }^{3}$ Essa disseminação da ideologia regionalista/nacionalista foi um dos meios pelos quais a política partidária divisória do final dos anos 20 - e isso inicialmente pode parecer como um paradoxo - antecipou a política "apolítica" de 1932, quando perrepistas e democráticos se uniram contra um inimigo comum. Como o uso do ícone do bandeirante indica, havia em jogo mais do que uma mera identificação com um lugar geográfico (com o que os nossos colegas mexicanistas chamariam de uma "patria chica") e conexões emocionais com este. De fato, esta identidade incluía uma lista de qualidades associadas ao estado de São Paulo, resumidas tão habilmente pelo cônsul geral dos Estados Unidos em agosto de 1932: "São Paulo has an extraordinary morale engendered by 20 months of

\footnotetext{
${ }^{2}$ ADDUCI, Cássia Chrispiano. A "pátria paulista": o separatismo como resposta à crise final do império brasileiro. São Paulo: Arquivo do Estado, 2000; WEINSTEIN, Barbara. "Racializing regional difference: São Paulo vs. Brazil, 1932”. In: Race and nation in modern Latin America. Nancy Appelbaum, Anne Macpherson e Karin Rosemblatt (orgs.). Chapel Hill: University of North Carolina Press, 2003, pp. 237-262, e correspondência com o autor.
} 
humiliation and the realization that it is fighting for its political position, its white man's culture, and the wealth, the lives, and the homes of its citizens" ( 'São Paulo tem uma moral extraordinária gerada por 20 meses de humilhação e pela consciência de que está lutando por sua posição política, sua cultura de homens brancos, e pela riqueza, vidas e lares de seus cidadãos'). ${ }^{4}$ Neste momento podemos lembrar o comentário de Katia Maria Abud sobre a figura do bandeirante: "O bandeirante representa, por excelência, a entidade paulista que se tornou sinônimo de bravura, integridade, arrojo, progresso, superioridade racial e até mesmo democracia".5

Essa identificação entre oposição política e paulistinidade era evidente antes mesmo da fundação do Partido Democrático. Em uma declaração publicada em setembro de 1925, o futuro líder honorário do partido, Antônio Prado, declarou: "Já tarda que os paulistas, filhos da terra dos verdadeiros grandes homens que contribuíram para a formação da nacionalidade brasileira, resolvam fundar um verdadeiro partido político, baseado nos princípios democráticos da nossa Constituição" 6 .

${ }^{3}$ Com algumas reservas, uso aqui o conceito habermasiano da "esfera pública" em uma maneira similar ao uso do conceito pela Hilda Sabato em suas pesquisas sobre a participação política na cidade de Buenos Aires durante o século dezenove. SABATO, Hilda. "Citizenship, political participation, and the formation of the public sphere in Buenos Aires, 1850s-1880s". Past \& Present. Oxford: Oxford University Press, 136, pp. 139163, 1992; idem, The many and the few: political participation in republican Buenos Aires. Stanford: Stanford University Press, 2001.

${ }^{4}$ Carta de C. R. Cameron a Walter C. Thurston, São Paulo Political Report No. 49, São Paulo, 9 de agosto de 1932, United States National Archives (USNA), College Park, Maryland, Record Group 59 (RG59), 832.00/811. Cameron foi muito ligado às pessoas que ele chamava de "better class Paulistas" e suas reportagens refletem essa familiaridade (citação de uma carta de C. R. Cameron a Walter C. Thurston, São Paulo Political Report No. 48, São Paulo, 30 de julho de 1932, USNA, RG59, 832.00/810). Ao contrário de Cameron, o embaixador norte-americano, baseado na capital federal de Rio de Janeiro, inclinou-se bem mais a responsabilizar os próprios paulistas pela "revolução" de 1932, explicando que "The fanatical attitude of the population must be broken before the normal life of the city can be restored". Carta de E. V. Morgan a Secretary of State, Rio de Janeiro, 14 de otubro de 1932, USNA, RG59, 832.00/818.

5 ABUD, Katia Maria. "O bandeirante e o movimento de 32: alguma relação?”. In: $O$ imaginário em terra conquistada, Maria Isaura Pereira de Queiroz (org.). São Paulo: Centro de Estudos Rurais e Urbanos,1993, p. 36.

6 "O voto secreto", O Estado de S. Paulo, 1 de setembro de 1925, p. 3. 
No primeiro comício público do novo partido, os líderes se esforçaram para acentuar o "nacionalismo" do PD e minimizar o seu regionalismo (presumivelmente para atrair apoio fora de São Paulo), com Luiz Augusto de Queiroz Aranha afirmando: "A nossa ação partidária começa em S. Paulo sem que tenhamos em mente o menor vislumbre de regionalismo. Daqui partem os primeiros passos, os mais custosos sem dúvida, mas que não contam ainda e que só contarão quando a eles se ajuntarem outros passos, muitos passos, depois de longas jornadas até que trema o solo pátrio ao tropel de um grande partido nacional. $\mathrm{Ou}$ nós, os brasileiros, executaremos este programa de homens livres, altivos, conscios dos seus deveres para com a Pátria ou seremos indignos da soberania desta formosa terra, pela qual o Cruzeiro do Sul luminosamente vela". ${ }^{7}$

Com a fundação do PD, uma espécie de identidade nacionalista/regionalista menos evidente na correspondência política dos líderes republicanos tornou-se uma constante na correspondência dos aderentes ao novo partido. Apelos patrióticos foram combinados com referências à preeminência de São Paulo na federação e a símbolos desta preeminência, dos quais o mais importante era o bandeirante. Em Altinópolis, Simplício Ferreira, um dos primeiros aderentes, previu que o PD "vai ser, em breve, o crisol da política nacional, especialmente da do Estado [de São Paulo], pelo qual mais nos interessamos". ${ }^{8}$ Ferreira foi seguido por um negociante de Bernardino de Campos que previu que com a fundação do partido dissidente "havemos de ver o reerguimento da Terra Paulista e da Pátria Brasileira". ${ }^{9}$ O comitê local do PD na cidade histórica de Itu saudou a liderança central do partido como grandes brasileiros e líderes "do grande movimento de civismo para o qual ora convergem as esperanças e o apoio populares e que, reflectindo-se pelo País inteiro, abala os velhos alicerces da tradicional Terra dos Bandeirantes", destinado a levar adiante os sonhos de antigos patriotas de criar “Um Brasil livre, ordeiro, progressista e 'ipso facto', feliz”. ${ }^{10}$

\footnotetext{
${ }^{7}$ PRADO, Nazareth (org.). Antonio Prado no imperio e na republica. Rio de Janeiro: F. Briguet, 1929, pp. 423-424.

${ }^{8}$ Carta de Simplício Ferreira a Antônio Prado, Altinópolis, 24 de março de 1926, Arquivo do Instituto Histórico e Geográfico de São Paulo (AIHGSP), Arquivo Partido Democrático (APD), pacote 33.

${ }^{9}$ Carta de Manuel Ahies [?] a "Illustre Commição Diretora do Partido Democratico", Bernardino de Campos, 18 de abril de 1926, AIHGSP, APD, pacote 33.

${ }^{10}$ Carta de Joaquim da Fonseca Bicudo et al. ao Diretório Provisório do PD, Itu, 29 de junho de 1926, AIHGSP, APD, pacote 33.
} 
Representantes da liderança central do partido enviados para o interior ecoavam esses temas em seus discursos públicos. Em um discurso em Jaú, Waldemar Ferreira propôs perante um público de "Mais de mil pessoas" que os paulistas estavam destinados a liderar a renovação nacional:

Estava S. Paulo fadado para ser o ponto de cristalisação desse grande empreendimento político, porque, como disse Cincinato Braga, "está na massa do sangue do paulista a preocupação indefesa de pertencer a uma pátria que se imponha ao mundo pela amplitude de seu território, pelo valor de suas riquezas, pelo brilho intelectual e moral dos seus filhos". Mas não somente por isso. Principalmente porque a responsabilidade de S. Paulo, na integração territorial e política do Brasil, desde o bandeirismo até a proclamação da República, lhe impõe a obrigação de caminhar para a sua finalidade historica. ${ }^{11}$

Este discurso foi "constantemente interrompido por vibrantes aplausos", segundo um artigo publicado no jornal $O$ Estado de S. Paulo. ${ }^{12}$

Plínio F. da Silva, um negociante paulista, escreveu ao Diretório Central do partido depois de ter lido o discurso de Waldemar Ferreira em um jornal. Silva, como "brasileiro legítimo..., principalmente paulista, amante do progresso e da ordem, da justiça, do trabalho legítimo e honesto", ficou extremamente entusiasmado com o discurso. A carta dele revela uma mistura estranha mas não incomum de identidade regionalista, reformismo desenvolvimentista, pessimismo, ufanismo, paternalismo, liberalismo e insegurança nacionalista:

Senhores Democratas, precisamos reagir. Ou novamente proclamamos a independência do Brasil ou daqui há dez ou vinte annos isto aqui não passará de uma colônia à feição do Norte da África. Precisamos restabelecer entre brasileiros o reino da justiça: precisamos acabar com as oligarquias, principalmente essa terrível de nosso querido Estado: precisamos dar alento ao povo brasileiro: precisamos curá-lo dos males físicos: precisamos ensiná-lo a ler: a trabalhar, a prezar a si próprio, a respeitar o seu próprio direito e o alheio: precisamos estimulá-lo ao amor de seu país que lhe oferece oportunidades aos milhões para viver ar-

\footnotetext{
11 "Partido Democrático", O Estado de S. Paulo, 27 de abril de 1926, p. 6.

${ }^{12}$ Ibid.
} 
ranjado, contente e feliz: precisamos mostrar ao nosso povo que o governo não é pai de ninguem e simplesmente exerce as funções de regulador da vida político [e] econômico da nação, bem como a social: precisamos dizer ao nosso povo que procure trabalhar com inteligência, persistência, honestidade, cada vez mais e melhor, porque o Governo lhe GARANTE estabilidade, facilidade de crédito, de transporte, de propaganda e finalmente de colocação de tudo quanto se produzir. Senhores Democratas, precisamos voltar neste país a ser homens de bem, a viver de acordo com os preceitos de nossa bela religião, a sã moral e o bom senso comum de toda gente. Estou a crer que o mundo inteiro se ri de nós por nos verem possuidores de uma das mais belas e das mais ricas regiões do globo, sem, no entanto irmos para frente..$^{13}$

Silva identificava a si mesmo e aos fundadores do PD como "bandeirantes", acrescentando: "Auspiciosamente o Brasil inteiro acredita em S. Paulo. S. Paulo é o Brasil. De novo gritemos Independência ou Morte!". ${ }^{14}$

Uma reivindicação chave, clara em alguns dos discursos citados acima, era que a modernização política não havia acompanhado o surpreendente progresso material do estado durante os últimos quarenta e poucos anos. Um escritor na cidade de Faxina, escrevendo num jornal habilmente chamado $O$ Progresso, ecoou Monteiro Lobato, o pai do Jeca Tatu, declarando que

O caipira nada vale. Carcomido pelas molestias, perece, no matto, enquanto os norte americanos com a missão "Rockefeller" tentam salval-o, apezar de estrangeiros... São Paulo tem escolas, estradas de ferro; cafezais; boa justiça - [mas] péssima política. Graças ao clima e qualidades da terra e ainda às correntes imigratórias, o estado é rico e próspero.

Mas, até hoje não tinha oposição política superiormente organizada. .... O Partido Democrático é a oposição dentro da lei que vem apelar para os homens de boa vontade e independentes para o trabalho reconstrutor da nação, roubada desde $89 .{ }^{15}$

\footnotetext{
${ }^{13}$ Carta de Plínio F. da Silva aos "Diretores do Partido Democrata", Rio de Janeiro, 29 de abril de 1926, AIHGSP, APD, pacote 48.

${ }^{14}$ Ibid.

15 "Pelos direitos do povo", recorte de jornal (O Progresso [Faxina], 10 de agosto de 1927), AIHGSP, APD, album VI.
} 
Os jornais foram um espaço especialmente importante para a divulgação da identidade regionalista/nacionalista. Cássia Chrispiniano Adduci mostrou a importância do Diário Nacional do PD, cujo título já sintesiza sua pretenção à status "nacional" (e nacionalista), assim como a Revista do Brasil, excelentemente examinada por Tania Regina de Luca. ${ }^{16}$ Mais uma vez, apela-se ao mito do bandeirante:

As terras, como as criaturas humanas, nascem de si apontadas aos seus destinos heróicos ou vulgares. .... S. Paulo, célula geográfica da nacionalidade, haveria de ter, nos seus primordios, o germe revelador de seus belos destinos. ......... A fusão do sangue luso, plasmador de navegadores e de guerreiros, com a raça altiva dos índios, teria que florir no tipo audaz do bandeirante, mixto de sonhador e de soldado, evangelizador de selvas e conquistador de montanhas. Enquanto as outras florescências da nova raça americana mal cobriam com a sua sombra a região do seu nascimento, o paulista antepoz-se ao tempo, sempre e cada vez mais dilatado.

Depois da conquista da terra na extensão geográfica, veio a conquista do solo, no esplendor das atividades agrícolas.... O trabalho dos novos bandeirantes deu ao Brasil a maior indústria agrícola do mundo, fulcro gigantesco da economia nacional. ${ }^{17}$

Na época o Diário Nacional era o segundo ou terceiro jornal mais vendido em São Paulo, segundo um observador. ${ }^{18}$

Como reação à intensa identidade regionalista-nacionalista dos democráticos, os oponentes perrepistas buscaram identificar o seu partido com São Paulo e com um projeto semelhante. Em um discurso numa próspera cidade do interior, Alexandre Marcondes Filho louvou o "esforço criador do paulista",

\footnotetext{
${ }^{16}$ ADDUCI, Cássia Chrispiniano. "O reforço da 'mística paulista' nas páginas do Diário Nacional". Lutas sociais. São Paulo: Pontifícia Universidade Católica de São Paulo, 7 , pp. 101-114, 2001; DE LUCA, Tania Regina. A "Revista do Brasil”: um diagnóstico para a (n)ação. São Paulo: Editora da UNESP, 1998.

${ }^{17}$ Diário Nacional, 1 de abril de 1928, citado em ADDUCI, op cit., pp. 113-114.

${ }^{18}$ C. R. Cameron, Report \# 151, "São Paulo Press on the Kellogg Pact”, São Paulo, 4 Sept. 1928, USNA, Record Group 84, American Consulate, São Paulo, Correspondence, 1928, vol. 7; idem, Report \#167, "Fascism in São Paulo", São Paulo, 29 Oct. 1928, in: ibid.
} 
rejeitando a identificação do PD com a paulistinidade e declarando-se contra a importação do voto secreto baseado no fato de que os brasileiros não deviam abandonar suas tradições, "o subsolo da nacionalidade". ${ }^{19}$

A eleição presidencial de 1930, quando o paulista Júlio Prestes de Albuquerque competia com a coalizão gaúcho-mineiro por trás de Getúlio Vargas, constitui-se uma grande oportunidade para os partidários do estadista de Itapetininga (a maioria deles clientes políticos do PRP) ostentarem sua boa fé paulista e denunciarem seus oponentes como desleais e desrespeitosos para com o orgulho paulista. $\mathrm{O}$ arquivo pessoal de Júlio Prestes oferece inúmeros exemplos deste tipo de expressão, o que contrasta significativamente com a correspondência anterior, na qual tal expressão é quase muda, quando não totalmente ausente.

Uma carta de um ex-democrático fornece um dos melhores exemplos deste tipo de identidade. Voltando de uma viagem ao Rio Grande do Sul, Antônio Amaral Mello endereçou uma carta a Júlio Prestes, em que, como "paulista amante de sua terra natal", explicou que naquele estado meridional havia visto "um furor belicoso" nos "comícios e... proclamações populares" da Aliança Liberal. Agora afastado do PD, ele ofereceu seu apoio ao "nosso Presidente do Estado, que encarna neste momento trevoso para a segurança da Pátria, um estadista capaz de assegurar a integridade de S. Paulo e manter a [sua] hegemonia no concerto da Federação". ${ }^{20}$

Nestor Siqueira de Macedo, o primeiro juiz de paz em exercício do distrito de Ipiranga, protestava sua "inteira solidariedade" à candidatura da situação paulista, declarando que "Minas Gerais só tem vida ao lado do Governo Federal, amparada pelo progresso de S. Paulo". ${ }^{21}$ Xará de um antigo cliente de Fernando Prestes (pai do presidente estadual), o "modesto patrício" Pedro Voss Filho prometeu a sua "solidariedade, neste momento em que está em jogo além

\footnotetext{
${ }^{19}$ Alexandre Marcondes Machado, "Conferência política realizada na cidade de Jaú, por ocasião do primeiro comício de propaganda do Partido Republicano Paulista, reproduzido de acordo com as notas tacquigráficas, em 1926", CPDOC, Arquivo Marcondes Filho, doc. pi 1926.00.00.

${ }^{20}$ Carta de Antônio Amaral Mello a Júlio Prestes de Albuquerque, São Paulo, 22 de setembro de 1929, Arquivo do Estado de São Paulo (AESP), Arquivo Júlio Prestes de Albuquerque (AJPA), caixa AP11.

${ }^{21}$ Carta de Nestor Siqueira de Macedo a Júlio Prestes de Albuquerque, São Paulo, 13 de agosto de 1929, AESP, AJPA, caixa AP10.
} 
do seu nome, de notavel republicano, o do meu grande Estado". ${ }^{22}$ Em São Bento do Sapucaí, a cidade natal de Plínio Salgado, Luís Gonzaga Raposa (um aliado do futuro chefe do fascismo brasileiro) mobilizou o "seu" eleitorado para votar em Júlio Prestes, "para [o] orgulho de São Paulo e para [a] grandeza do Brasil". ${ }^{23}$ E, no município de Itatinga, um funcionário público manifestou sentimentos bem similares, protestando sua solidariedade à candidatura perrepista "porque o seu lema é: TUDO PELO DR. JÚLIO PRESTES E TUDO PELO BRASIL". ${ }^{24}$

Monteiro Lobato, escrevendo de Nova York, congratulou o candidato perrepista e ofereceu o seu apoio:

primo) porque está em causa Júlio Prestes;

secundo) porque sua política na presidência significará o de que mais precisa o Brasil: continuidade administrativa; tercio) porque é tempo do posto supremo ser ocupado por um moço. ${ }^{25}$

Finalmente, concluiu Lobato, "porque não é com queijo, nem carne seca que os graves problemas que defrontam o Brasil serão resolvidos. É com café, audácia, visão, iniciativa e as mais outras qualidades yankees que caracterizam o paulista" ${ }^{26}$

O próprio Vargas teve que apelar à estes valores durante a sua campanha eleitoral. Em janeiro de 1930 o candidato gaúcho declarou:

Paulistas! Glorioso povo paulista! Terra bem fadada que permitiu o surto dos bandeirantes, raça privilegiada, que desbravou a terra e lançou as bases de uma civilização nova. Daqui partiu o grito da independência, na colina simbólica do Ipiranga, na palavra dos oradores e na vibração cívica dos comícios prepararam-se as campanhas da abolição e da República.

\footnotetext{
${ }^{22}$ Carta de Pedro Voss Filho a Júlio Prestes de Albuquerque, Tatuí, 17 de setembro de 1929, AESP, AJPA, caixa AP11; O Estado de S. Paulo, 22 de dezembro de 1909, p. 4.

${ }^{23}$ Carta de Luiz Gonzaga Raposa a Júlio Prestes de Albuquerque, São Bento de Sapucaí, 31 de janeiro de 1930, AESP, AJPA, caixa AP14.

${ }^{24}$ Carta de Chrispiano Cid Costa a Júlio Prestes de Albuquerque, Itatinga, 16 de janeiro de 1930, AESP, AJPA, caixa AP14.

${ }^{25}$ Carta de Monteiro Lobato a Júlio Prestes de Albuquerque, Nova York, 28 de agosto de 1929, citado em DEBES, Célio. Júlio Prestes e a primeira república. São Paulo: Imprensa Oficial, 1982, p. 96.

${ }^{26}$ Ibid.
} 
Todas as forças dinâmicas da nacionalidade, todos os grandes movimentos que agitaram a alma da raça, quando não partiram de S. Paulo, encontraram em seu seio um eco vibrante e decisivo. ${ }^{27}$

Nem todos, claro, estavam entusiasmados com este tipo de identidade e com a forma como ele saturava o discurso político da época. Nas paginas do Diário da Noite, J. Canuto declarou:

Nunca é demasiado queixar-se a gente desses excessos de regionalismo que as coisas e os homens da República vêm reacendendo, cada vez mais, no coração do Brasil. A unidade nacional - patrimônio a nós legado pelas gerações passadas à custa de ingentes sacrificios - vai sofrendo, pouco a pouco, quase imperceptivelmente, pequeninos golpes, mais permanentes, que divorciam, sempre e em todos os Estados, as diversas regiões do país.

Os Estados brasileiros - quase todos - têm a sua bandeira. Oficial ou não, esse símbolo existe, como uma imposição de regionalismo à massa anônima.

Em São Paulo, não só o povo, mas até as agremiações políticas, timbram em frisar o caráter regionalista de toda a sua atividade: ostentam, nas festas e comemorações cívicas, o pano de listas pretas e canto vermelho, reconhecido como "a bandeira paulista".

O Partido Democrático, num dos seus congressos, único a que assisti, instalou a bandeira paulista ao lado da bandeira brasileira, como se fora coisa muito natural e justa. O Partido Republicano Paulista adotou como distintivo o mesmo desenho da flâmula de S. Paulo. ${ }^{28}$

Antecipando o Estado Novo, Canuto pedia a proscrição das bandeiras estaduais e, de uma maneira geral, pelo fim da identificação regionalista. Entretanto, mesmo esse escritor anti-regionalista foi incapaz de se expressar sem recorrer àquele símbolo mais paulista de todos, o bandeirante, declarando que "O culto dos bandeirantes... deve ser acoroçoado para que toda a gente, desde

\footnotetext{
27 "Como foram recebidos os candidatos liberais", O Estado de S. Paulo, 5 de janeiro de 1930 , p. 6.

${ }^{28}$ J. Canuto, "Campanha em prol da unidade nacional", recorte de jornal (Diário da Noite, 11 de setembro de 1929), AIHGSP, APD, pacote 59.
} 
o Amazonas até o Prata, se convença definitivamente de que a maior riqueza que nos legaram os nossos maiores foi essa enorme Pátria una e coesa". ${ }^{29}$

O comentário de Canuto indica como símbolos - bandeiras, insígnias, e seu uso em relação aos outros - foram muito importantes na difusão da identidade regionalista. Um pôster do famoso cartunista Belmonte (Benedicto Carneiro Bastos Barreto) serve como uma ótima ilustração deste ponto. O pôster mostra um bandeirante muito branco em pé com uma cédula eleitoral em uma mão e uma espada etiquetada "Partido Democrático" na outra, de frente para três figuras bem menores: um "eleitor de cabresto" afro-descendente, um eleitor estrangeiro, e um "fósforo eleitoral" dando uma olhada por trás de uma lápide. A legenda diz: "De Pé, S. Paulo! Nas eleições de 24 de fevereiro, com esta arma, defender-te-ás do assalto dos pigmeus!" 30 Ao descrever o bandeirante deste modo, Belmonte estava ecoando materiais iconográficos mais antigos (a propaganda da Liga Nacionalista da década anterior) e antecipando o uso do bandeirante como um ícone na propaganda da revolta de $1932 .{ }^{31}$

Pode-se também observar que a racialização da figura do bandeirante (e do eleitor de cabresto) ecoava debates sobre o voto secreto que se remontavam 52 às décadas de 1910 e 1920 . Na época, a reforma eleitoral foi comparada à abolição da escravidão. Intelectuais proeminentes sugeriam que o Brasil tinha sido "o último [país] a proclamar a liberdade do negro e pode ser o derradeiro a libertar a consciência do branco" através da introdução do voto secreto, descrito como "um 13 de Maio branco" e que legitimamente seria introduzido primeiro em São Paulo, já que o estado desempenhava seu papel natural de "leader da união", depois do que, "por contágio, [a liberdade de consciência] dominando o país inteiro, e o Brasil começaria, enfim, a matar esse atraso de cem anos a que a dupla escravidão do corpo do preto, outrora, e da consciência do branco, hoje". ${ }^{32} \mathrm{O}$ "13 de Maio branco" foi um tema importante na correspondência

\footnotetext{
${ }^{29}$ Ibid.

${ }^{30}$ AIHGSP, APD, pacote 13, item 8. O pôster é reproduzido em SÃO PAULO, Assembléia Legislativa. Legislativo paulista: parlamentares, 1835-1999. Auro Augusto Caliman (org.). 2a. edição, São Paulo: Imprensa Oficial, 1999, p. 77.

${ }^{31}$ Pôster de propaganda promovendo o alistamento eleitoral, AIHGSP, Arquivo Liga Nacionalista, pacote 1. O pôster é reproduzido em SÃO PAULO, op cit., p. 71. Para a manipulação da imagem do bandeirante em 1932, ver ABUD, op cit., pp. 41-44.

${ }^{32}$ LOBATO, Monteiro et al. O voto secreto: carta aberta ao Exmo. Snr. Dr. Carlos de Campos. São Paulo: 1924.
} 
da oposição política. Notamos isso, por exemplo, numa carta de um partidário do PD que orgulhosamente diz: "Lancei o meu humilde nome na lista dos combatentes pelo 13 de Maio branco", identificando-se com a "gente de bem" do partido. ${ }^{33}$ A referência ao "13 de Maio branco" teria eco no início dos anos 30 no discurso regionalista racializado descrito tão bem por Barbara Weinstein. ${ }^{34}$

Nos anos que se seguiram, a identidade paulista encontrou ecos importantes em livros, artigos, comemorações públicas, e até em correspondências particulares. Podemos encontrar exemplos disto na excelente introdução que Vavy Pacheco Borges faz sobre esse tema em sua Memória paulista ou numa carta endereçada a Paulo Duarte em meados dos anos trinta em que a correspondente (uma paulista) declarou: "Odeio aos brasileiros, e ao jugo deles prefiro o estrangeiro". ${ }^{35}$ Mesmo os seguidores do major Miguel Costa, que naquele momento apoiou o governo federal encabeçado por Getúlio Vargas, declaravam no início dos anos trinta que o seu herói, apesar de ter nascido em Buenos Aires, tinha "coração paulista". ${ }^{36}$

Depois do fracasso da rebelião de 32, as marcas da superioridade paulista (a aclamada modernidade, civilização, dinamismo econômico, e "brancura" de São Paulo) foram unidas à evocação do sacrifício nas trincheiras. $\mathrm{O}$ "constitucionalismo" paulista era identificado com sacrifício e não com precedentes liberais, com "dever" em vez de com "reforma". Em 1934, por exemplo, o Partido Constitucionalista (recém fundado pela coligação da Federação dos Voluntários de São Paulo, os dissidentes perrepistas da Ação Nacional, e os membros restantes do $\mathrm{PD}^{37}$ ) distribuíram panfletos que mostravam soldados caídos na guerra olhando de cima para a cidade de São Paulo com uma legenda que dizia: "Cumprimos o nosso dever: cumpra agora o seu! Vote no Partido

\footnotetext{
${ }^{33}$ Antonio Monteiro da [ilegível] aos diretores do PD, São Paulo, 27 de março de 1926, AIHGSP, APD, pacote 45.

${ }^{34}$ WEINSTEIN, op cit.

35 BORGES, Vavy Pacheco. Memória paulista. São Paulo: Editora da Universidade de São Paulo, 1997, capítulo 3; DUARTE, Paulo. Memórias. São Paulo: Hucitec, 1974-1980, volume 2, p. 187.

${ }^{36}$ BEZERRA, Holien Gonçalves. O jogo do poder: revolução paulista de 32. São Paulo: Editora Moderna, 1989, p. 101.

${ }^{37}$ RAMOS, Plínio de Abreu. "Partido Constitucionalista de São Paulo". In: Dicionário histórico-biográfico brasileiro. Alzira Alves de Abreu et al. (orgs.). 2a. edição. Rio de Janeiro: Editora da Fundação Getúlio Vargas, 2001, p. 4283.
} 
Constitucionalista". ${ }^{38}$ Neste discurso, a própria revolta torna-se uma espécie de equivalente paulista do "bloody shirt" da pós-Guerra Civil do nordeste e Meio Oeste dos Estados Unidos (símbolo do sacrifício da guerra e do martírio do presidente Abraham Lincoln para membros do Partido Republicano da época), um ponto de referência a que todo político ambicioso tinha que se referir. De fato, o poder emotivo de 1932 parecia tão forte que em certos momentos específicos até a esquerda internacionalista usou este mesmo apelo ao tentar conseguir apoio popular. Em 1935, por exemplo, quando Luís Carlos Prestes convocou a "frente única revolucionária”, ele apelou para a "juventude heróica de São Paulo que pensou defender nas trincheiras de 1932, a democracia e a liberdade contra a ditadura de Vargas". 39

Esse tipo de apelo ecoava um discurso regionalista mais amplo, com origens no século dezenove. O final dos anos vinte - e, em particular, o conflito político entre o PD e o PRP - foi um dos muitos momentos em que este discurso foi ensaiado e incitado.

\section{Referências Bibliográficas}

ABUD, Katia Maria. "O bandeirante e o movimento de 32: alguma relação?”. In: O imaginário em terra conquistada, Maria Isaura Pereira de Queiroz (org.). São Paulo: Centro de Estudos Rurais e Urbanos, 1993.

ADDUCI, Cássia Chrispiano. A "pátria paulista”: o separatismo como resposta à crise final do império brasileiro. São Paulo: Arquivo do Estado, 2000.

ADDUCI, Cássia Chrispiniano. “O reforço da 'mística paulista' nas páginas do Diário Nacional”. Lutas sociais. São Paulo: Pontifícia Universidade Católica de São Paulo, 7, 2001.

${ }^{38} \mathrm{O}$ pôster é reproduzido em SÃO PAULO, op cit., 107.

${ }^{39}$ A Manhã (Rio de Janeiro), 5 de julho de 1935 (2a edição), citado em FONSECA, Vitor Manoel Marques da. "A ANL na legalidade". Tese de mestrado da Universidade Federal Fluminense, 1986, p. 236. Emquanto o PCB estava na legalidade, em meados dos anos quarenta, biografias oficiais de certos candidatos do partido fizeram referências especiais à participação dos candidatos nos eventos de 1932. Ver as biografias de Catullo Branco e Milton Cayres de Brito, Hoje (São Paulo), 21 de novembro de 1945, p. 8, e 26 de novembro de 1945 , p. 6. 
BEZERRA, Holien Gonçalves. O jogo do poder: revolução paulista de 32. São Paulo: Editora Moderna, 1989.

BORGES, Vavy Pacheco. Memória paulista. São Paulo: Editora da Universidade de São Paulo, 1997.

DE LUCA, Tania Regina. A "Revista do Brasil": um diagnóstico para a (n)ação. São Paulo: Editora da UNESP, 1998.

DEBES, Célio. Júlio Prestes e a primeira república. São Paulo: Imprensa Oficial, 1982.

DUARTE, Paulo. Memórias. São Paulo: Hucitec, 1974-1980.

FONSECA, Vitor Manoel Marques da. "A ANL na legalidade". Tese de mestrado da Universidade Federal Fluminense, 1986.

LOBATO, Monteiro et al. O voto secreto: carta aberta ao Exmo. Snr. Dr. Carlos de Campos. São Paulo: 1924.

MORGAN, Arthur. Os engenheiros de S. Paulo em 1932: pela lei e pela ordem. São Paulo: 1934.

OLIVEIRA, Clovis de. A indústria e o movimento constitucionalista de 1932. São Paulo: Serviço de Publicações do CIESP/FIESP, 1956.

PRADO, Maria Lígia Coelho. A democracia ilustrada: o Partido Democrático de São Paulo, 1926-1934. São Paulo: Editora Ática, 1986.

PRADO, Nazareth (org.). Antonio Prado no imperio e na republica. Rio de Janeiro: F. Briguet, 1929.

RAMOS, Plínio de Abreu. "Partido Constitucionalista de São Paulo". In: Dicionário histórico-biográfico brasileiro. Alzira Alves de Abreu et al. (orgs.). 2a. edição. Rio de Janeiro: Editora da Fundação Getúlio Vargas, 2001.

SABATO, Hilda. "Citizenship, political participation, and the formation of the public sphere in Buenos Aires, 1850s-1880s". Past \& Present. Oxford: Oxford University Press, 136, 1992.

. The many and the few: political participation in republican Buenos Aires. Stanford: Stanford University Press, 2001.

SANTOS, Francisco Martins dos. História de Santos, 1532-1936. São Paulo: Empreza Graphica da Revista dos Tribunaes, 1937.

SÃO PAULO, Assembléia Legislativa. Legislativo paulista: parlamentares, 1835-1999. Auro Augusto Caliman (org.). 2a. edição, São Paulo: Imprensa Oficial, 1999. 
WEINSTEIN, Barbara. For social peace in Brazil: industrialists and the remaking of the working class in São Paulo, 1920-1964. Chapel Hill: University of North Carolina Press, 1996.

. "Racializing regional difference: São Paulo vs. Brazil, 1932". In: Race and nation in modern Latin America. Nancy Appelbaum, Anne Macpherson e Karin Rosemblatt (orgs.). Chapel Hill: University of North Carolina Press, 2003. 